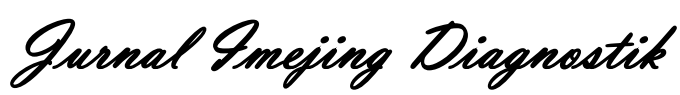

e-ISSN 2621-7457, p-ISSN 2356-301X

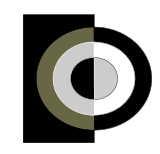

http://ejournal.poltekkessmg.ac.id/ojs/index.php/jimed/index

\title{
Rancang Bangun Alat Bantu Pemeriksaan Knee Joint Pada Kasus Osteoarthritis
}

\author{
Bagus Dwi Handoko을 Agung Bayu Pamungkas ${ }^{2}$, Akhmad Haris Sulistiyadi $^{3}$ \\ 1,2,3 Poltekkes Kemenkes Semarang, Indonesia \\ Corresponding Author: Bagus Dwi Handoko \\ e-mail : barrabirrugood@gmail.com
}

Received: Juni $18^{\text {th }}$, 2020; Revised: January $31^{\text {st }}$, 2021; Accepted: February $1^{\text {st }}, 2021$

\begin{abstract}
Background : The Knee joint is a hinge joint with a change formed by the two condyls of the femur that are jointed with the superior surface of the tibial tube. Radiographic examination of the knee joint on AP weight bearing and lateral weight bearing projections is a good projection in revealing joint gaps in the knee joint. The constraints on this examination are when patients who have little difficulty standing on one leg when doing lateral projection of weight bearing. So that a knee joint examination tool is needed in the case of osteoarthrithis.

Methods : The purpose of this study was to describe the design, study the function tests and performance tests of knee joint hearing aids in the case of osteoarthrithis.This research is a type of experimental research with the design of a one shoot case study. Data collection is obtained by a check list of results of functional tests and performance test tools. The data obtained was assessed by Guttman's scale and conclusions and suggestions were drawn. This study produced a design in the form of a knee joint examination tool. The tool is made of stainless steel pipes, on a pedestal made of wooden boards, foam and cloth. Based on the calculation of the check list using the Guttman scale.

Result: The function test results were $100 \%$ and the performance test results were $96 \%$. Until the knee joint examination tool in the case of osteoarthrithis is said to be feasible to use.

Conclusion : This knee joint examination aid has a number of parts, a pedestal made of wood sheets, adjustable footrests, and a patient's padded arms. The auxiliary framework uses a $3 \mathrm{~cm}$ diameter stainless steel pipe with a thickness of $1 \mathrm{~mm}$. Based on the functional tests in the Radiology Installation of Prof. Dr. Margono Soekarjo Purwokerto obtained results $100 \%$ for knee joint examination in osteoarthritis cases with AP weight bearing projections and lateral weight bearing. Based on performance tests which involved 5 respondents who were radiographers were said to be very appropriate with a percentage of $96 \%$ with an excess of ease in operation, reducing the movement of patients, and helping the radiographers to produce informative radiographs.
\end{abstract}

Keywords :Knee Joint Tool;Osteoarthritis; AP Weight Bearing Projection

\section{Pendahuluan}

Bidang radiologi merupakan salah satu penunjang pelayanan kesehatan yang dipergunakan untuk mengetahui anatomi dan fisiologi organ tubuh manusia. Perkembangan ilmu pengetahuan dan teknologi di bidang radiologi sangat diperlukan untuk menghasilkan gambaran radiograf yang berkualitas. Kualitas radiograf dapat dinilai baik jika radiograf dapat memberikan informasi secara jelas, sehingga dapat membantu menegakkan diagnose dokter dan sebagai penentu langkah selanjutnya yang akan dilakukan terhadap pasien. Salah satu pemeriksaan radiologi yang biasa dilakukan adalah pemeriksaan knee joint.
Sendi lutut (knee joint) adalah sendi engsel dengan perubahan yang dibentuk oleh kedua kondil femur yang bersendi dengan permukaan superior dari kondil tibia. Patella terletak diatas permukaan pateler yang halus pada femur dan diatas itu patella meluncur sewaktu sendi bergerak. Patella berada di depan bagian-bagian persendian yang utama, tetapi tidak masuk ke dalam formasi sendi lutut (Pearce, 2016).

Menurut Lampignano (2018) dan Helmi (2012), beberapa kelainan dapat terjadi pada knee joint antara lain fracture, lesion, kelainan pada joint space, dislokasi, dan osteoarthritis. Osteoarthritis merupakan suatu penyakit degeneratif pada persendian yang disebabkan 
oleh beberapa faktor. Penyakit ini mempunyai karakteristik berupa terjadinya kerusakan pada cartilage (tulangrawansendi). Osteoarthritis sering disebut juga degenerative joint disease (DJD), yaitu peradangan pada joint atau sendi yang ditandai dengan berdegeneratifnya tulang rawan dan disertai dengan hyperthrophic (pembesaran) susunan tulang.

Menurut Frank (2012), untuk melakukan pemeriksaan radiografi knee joint pada kasus osteoarthritis memerlukan beberapa proyeksi yaitu proyeksi AP Weight Bearing atau posisi $P A$ Weight Bearing. Sedangkan menurut Keith dkk (2014), untuk melihat kelainan osteoarthritis pada knee joint merekomendasikan penggunaan proyeksi AP Weight Bearing Bilateral dan Proyeksi Skyline. Proyeksi AP Weight Bearing Bilateral digunakan untuk menilai terjadinya osteoarthritis di medial dan lateral tibial femoral joint, sedangkan posisi Skyline digunakan untuk menilai terjadinya osteoarthritis di bagian patella femoral joint. Kualitas radiograf didefinisikan sebagai ketepatan representasi dari bagian anatomi pasien pada radiograf. Kualitas radiograf yang baik diperlukan sehingga ahli Radiologi dapat membuat diagnose yang akurat (Bushong,2017). Salah satu faktor yang mempengaruhi kualitas radiograf adalah factor pergerakan yang dilakukan oleh pasien, oleh karena itu diciptakanlah berbagai macam alat fiksasi pasien atau alat bantu pemeriksaan untuk mengurangi pergerakan yang dilakukan pasien.

Alat bantu fiksasi pada pemeriksaan knee joint yang sudah ada antara lain adalah Adjustable-type leg support and IR holder, Softbbag, Sandbag, Gauze Bandage, box dari busa keras (Lampignano, 2018). Dari hasil observasi di Rumah Sakit saat penulis melakukan kegiatan PKL, penulis dan radiographer mengalami kesulitan saat memposisikan pasien pemeriksaan radiografi knee joint proyeksi antero-posterior (AP) dan lateral dengan kasus osteoarthritis. Kesulitan saat memposisikan pasien terjadi karena pasien sulit untuk menggerakan kaki dalam posisi erect (berdiri).

Posisi pasien dan hasil radiografi pada pemeriksaan radiografi knee joint denganposisi AP weight bearing dan Lateral wight bearing dengan menggunakan alat bantu pemeriksaan knee joint pada kasus osteoarthrithis sebagai berikut :
Oleh karena itu, penulis melakukan penelitian dengan membuat alat bantu untuk pasien supaya nyaman untuk membantu pemeriksaan knee joint denganjudul "RANCANG BANGUN ALAT BANTU PEMERIKSAAN KNEE JOINT PADA KASUS OSTEOARTHRITIS".

\section{Metode}

Jenis penelitian yang digunakan dalam karya tulis ilmiah ini adalah penelitian eksperimen dengan desain the one shoot case study dengan membuat alat bantu pemeriksaan knee joint pada kasus osteoarthritis

\section{Hasil dan Pembahasan}

\section{1) Hasil RancangBangun Alat Bantu Pemeriksaan Knee Joint Pada KasusOsteoarthrithis}

Setelah dilakukan pembuatan rancang bangun alat bantu pemeriksaan knee joint pada kasus osteoarthrithis, diperoleh hasil alat sebagai berikut :

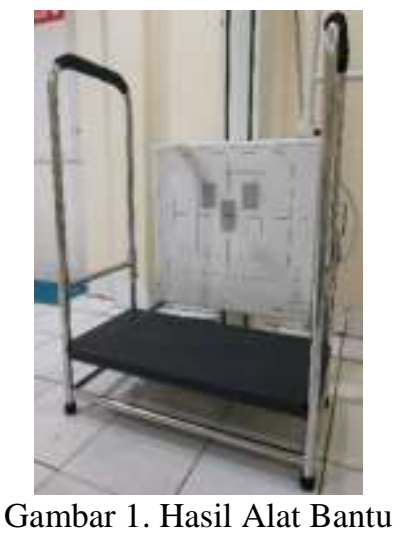

Alat bantu pemeriksaan knee joint tersebut memiliki dimensi tinggi $105 \mathrm{~cm}$, lebar kanan-kiri $75 \mathrm{~cm}$, lebar depan-belakang $35 \mathrm{~cm}$, tinggi alas dari permukaan lantai setinggi $20 \mathrm{~cm}$ dengan berat alat $7 \mathrm{~kg}$. Alat tersebut telah dilakukan pengujian dengan dinaiki oleh 2 orang yang memiliki beban $100 \mathrm{~kg}$ dan $54 \mathrm{~kg}$, sehingga alat tersebut mampu menahan beban $154 \mathrm{~kg}$.

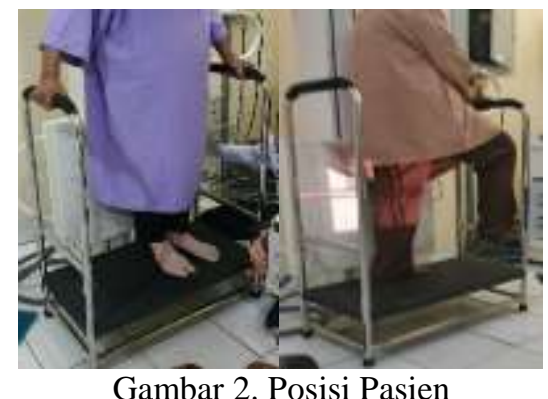


Bahan dan fungsi dari masing-masing bagian rancang bangun alat bantu pemeriksaan knee joint pada kasus osteoarthrithis sebagai berikut :

a) Kerangka alat bantu

Kerangka alat bantu pemeriksaan knee joint pada kasus osteoarthrithis menggunakan pipa stainless steel berdiameter $3 \mathrm{~cm}$ dengan ketebalan $1 \mathrm{~mm}$. Pada kerangka tersebut digunakan pipa stainless steel karena selain anti karat, bahan tersebut juga lebih ringan dari pada pipa besi.

b) Bagian alas tempat pasienberdiri

Bagian alas tempat pasien berdiri terbuat dari papan kayu yang dibungkus dengan busa tipis dan kain supaya pasien lebih nyaman saat berada di alat bantu tersebut dan juga menambah nilai estetika.

c) Penyangga kaki

Penyangga kaki terbuat dari pipa stainless steel yang berdiameter lebih besar dari pada diameter pipa kerangka supaya dapat diatur naik turun sesuai kebutuhan.

Rancang bangun alat bantu pemeriksaan knee joint pada kasus osteoarthrithis merupakan alat yang dirancang untuk membantu pemeriksaan radiografi knee joint proyeksi AP weight bearing dan lateral weight bearing. Berdasarkan hasil penelitian yang telah dilakukan pada alat bantu ini, alat bantu pemeriksaan knee joint pada kasus osteoarthrithis didesain sesuai dengan kondisi yang ada di lapangan, sehingga alat dapat menyesuaikan kebutuhan di lapangan dengan aman dan memberi rasa nyaman bagi pasien serta memberikan informasi diagnostik yang tepat atau informatif. Alat ini didesain sebagaialat bantu supaya pasien dapat berdiri dengan dua atau satu kaki dengan seimbang dan nyaman, selain itu alat tersebut juga sangat mempermudah radiographer untuk menginstruksikan pasien agar dapat berdiri satu kaki dalam posisi AP maupun lateral. Bahan alat tersebut menggunakan stainless steel yang menjadikan alat menjadi tidak mudah korosi serta mudah untuk dipindahkan ketika tidak dibutuhkan. Alat bantu tersebut didesain dan dirancang dengan cermat sehingga menghasilkan alat yang kuat dan mudahdigunakan.

Bagian alas tempat pasien berdiri menggunakan papan kayu yang ringan namun tetap dapat menahan beban yang berat, papan kayu diletakan di atas kerangka alat bantu kemudian diberi sekrup supayapapantidakter lepas dari kerangka, kemudian dilapisi dengan busa tipis dan kain supaya memberikan kenyamanan terhadap pasien dan juga menambah estetika. Di bagian alas menggunakan papan kayu guna mengurangi beban alat bantu tersebut. Meskipun pada bagian alas menggunakanpapankayu namun tetap sanggup menahan beban yang berathingga $154 \mathrm{~kg}$ yang diujidengandinaiki oleh 2 orang secarabersamaan yang memilikibeban $100 \mathrm{~kg}$ dan $54 \mathrm{~kg}$.

Pada bagianpenyangga kaki dibuatdengan pipa stainless steel berdiameter lebih besar dari pipa kerangka supaya penyangga kaki dapatdiatur naik atau turun sesuai dengan kebutuhan, serta pada pipa kerangkatelah diberi beberapa lubang dan terdapat sekrup untuk mengganjal penyangga kaki yang telah diatur naik atau turunnya.

Bagian pegangan di sisikanan dan kiri dilapisi oleh busa untuk kenyamanan pasien saat berpegangan pada alat tersebut. Dan juga pada keempat kaki alat bantu diberikan karet supaya alat tidak licin apabila diletakan di atas lantai keramik.

\section{2) Uji Fungsi Rancang Bangun Alat Bantu Pemeriksaan Knee Joint pada Kasus Osteoarthrithis}

Uji fungsi alat dilakukan untuk mendapatkan penilaian mengenai kelayakan alat bantu pemeriksaan radiografi knee joint pada kasus osteoarthrithis sebelum digunakan kepada pasien sebagai subyek penelitian, uji fungsi dilakukan di Instalasi Radiologi RSUD Prof. Dr.Margono Soekarjo Purwokerto yang didampingi oleh seorang radiografer.

Tabel 1.Hasil Uji Fungsi Alat

\begin{tabular}{|c|l|c|c|}
\hline \multirow{2}{*}{ No } & \multicolumn{1}{|c|}{ Pertanyaan } & \multicolumn{2}{|c|}{$\begin{array}{c}\text { Penilaian } \\
\text { Subyektif }\end{array}$} \\
\cline { 3 - 4 } & & Ya & Tidak \\
\hline 1 & Apakah alat bantu tersebut mampu menahan beban pasien? & 1 & 0 \\
\hline 2 & $\begin{array}{l}\text { Apakah alat tersebut tidak menimbulkan artefak pada } \\
\text { radiograf? }\end{array}$ & 1 & 0 \\
\hline 3 & $\begin{array}{l}\text { Apakah tempat penyangga kaki pada alat tersebut bekerja } \\
\text { dengan baik? }\end{array}$ & 1 & 0 \\
\hline 4 & $\begin{array}{l}\text { Apakah pada tempat penyangga kaki dapat diatur naik atau } \\
\text { turun sesuai dengan kebutuhan? }\end{array}$ & 1 & 0 \\
\hline 5 & $\begin{array}{l}\text { Apakah alat bantu tersebut dapat ditempatkan dengan baik } \\
\text { di depan bucky stand? }\end{array}$ & 1 & 0 \\
\hline
\end{tabular}

Berdasarkan perhitungan rekapan check list uji fungsi dengan rumusdiatas, didapatkan hasil uji fungsi sebesar $100 \%$ jadi, rancang bangun alat bantu pemeriksaan knee joint pada kasus osteoarthrithis dinyatakan layak untuk digunakan kepada pasien sebagai subyek penelitian dalam rangka pengambilan data untuk menilai uji kinerja rancang bangun alat bantu 
pemeriksaan knee joint pada kasus osteoarthrithis oleh 5 responden di Instalasi Radiologi RSUD Prof. Dr.Margono Soekarjo Purwokerto.

Uji fungsi merupakan pengujian secara keseluruhan melalui uji bagian-bagian alat kesehatan dengan kemampuan maksimum tanpa beban sebenarnya, sehingga dapat diketahui apakah secara keseluruhan alat kesehatan dapat dioperasikan dengan baik sesuai fungsinya (Permenkes, 2015). Uji fungsi alat dilakukan di Instalasi Radiologi RSUD Prof. Dr. Margono Soekarjo Purwokerto. Setelah dilakukan uji fungsi didapatkan hasil uji fungsi sebagai berikut

Hasil uji fungsi sebesar $100 \%$ yang menunjukkan bahwa rancang bangun alat bantu pada pemeriksaan radiografi knee joint dikatakan layak digunakan pada pasien pemeriksaan radiografi knee joint pada kasus osteoarthrithis. Hal ini karena seluruh komponen pada alat bantu pemeriksaan knee joint pada kasus osteoarthrithis seperti penyangga kaki berfungsi dengan baik, penyangga kaki dapat diatur naik atau turun sesuai kebutuhan, alat tersebut tidak menimbulkan artefak pada radiograf, alat bantu dapat ditempatkan dengan baik di depan bucky stand, serta alat bantu tersebut mampu menahan beban pasien. Penggunaan alat bantu inisudah dapat berfungsi sesuai dengan tujuan dan fungsinya masing masing sehingga alat bantu ini aman digunakan kepada pasien dengan pemeriksaan knee joint pada kasus osteoarthrithis dengan proyeksi AP weight bearing dan lateral weight bearing untukpengambilan data.

\section{3) Uji Kinerja Rancang bangun Alat Bantu Pemeriksaan Knee Joint pada Kasus Osteoarthrithis}

Uji kinerja alat dilakukan untuk mendapatkan penilaian dari 5 responden yang merupakan radiografer di Instalasi Radiologi RSUD Prof. Dr.Margono Soekarjo Purwokerto mengenai kelayakan alat bantu pemeriksaan knee joint pada kasus osteoarthrithis apabila digunakan pada pasien. Berikut ini hasil uji kinerja yang dilakukan terhadap 5 responden di Instalasi Radiologi RSUD Prof. Dr.Margono Soekarjo Purwokerto :
Tabel 2. Hasil Uji Kinerja Alat

\begin{tabular}{|c|l|c|c|}
\hline \multirow{2}{*}{ No } & \multicolumn{1}{|c|}{ Pertanyaan } & \multicolumn{2}{|c|}{$\begin{array}{c}\text { Penilaian } \\
\text { Subjektif }\end{array}$} \\
\cline { 3 - 4 } & Ya & Tidak \\
\hline 1 & Apakah alat ini dapat membantu kinerja radiografer? & 5 & 0 \\
\hline 2 & $\begin{array}{l}\text { Apakah alat tersebut dapat memudahkan radiografer } \\
\text { dalam positioning? }\end{array}$ & 5 & 0 \\
\hline 3 & $\begin{array}{l}\text { Apakah alat tersebut dapat mempercepat waktu } \\
\text { pemeriksaan? }\end{array}$ & 4 & 1 \\
\hline 4 & $\begin{array}{l}\text { Apakah alat tersebut kuat menahan beban pasien? } \\
5\end{array}$ & 5 & 0 \\
\hline $\begin{array}{l}\text { Apakah alat tersebut dapat mengurangi pergerakan pada } \\
\text { pasien? }\end{array}$ & 5 & 0 \\
\hline
\end{tabular}

Berdasarkan penghitungan rekap check list uji kinerja dengan rumus tersebut, didapatkan hasil uji kinerja sebesar 96\%, jadi rancang bangun alat bantu pemeriksaan knee joint pada kasus osteoarthrithis dapat dikatakan sangat layak digunakan kepada pasien dengan pemeriksaan radiografi knee joint pada kasus osteoarthrithis dengan proyeksi AP weight bearing dan lateral weight bearing.

Uji kinerja merupakan pengujian untuk mengetahui seberapa besar kinerja dari suatu alat kesehatan sehingga dapat digunakan sesuai dengan kebutuhan spesifikasi (Permenkes, 2015). Uji kinerja alat bantu pemeriksaan knee joint pada kasus osteoarthrithis dilakukan di Instalasi Radiologi RSUD Prof. Dr. Margono Soekarjo Purwokerto dengan melibatkan 5 responden yang terdiri dari 5 radiograferserta 5 sampel yang merupakan pasien dengan permintaan foto knee joint dengan posisi AP weight bearing dan lateral weight bearing. Setelah dilakukan uji kinerja selama satu bulan pengambilan data didapatkan hasil sebesar 24 jawaban mendukung kelayakan alat bantu pemeriksaan knee joint dan merupakan kelebihan dari alat bantu ini berdasarkan system scoring menggunakan skala Guttman pada lembar check list dan berdasarkankondisisaat di ujikan di lapangan yaitu sebagai berikut :

a. Alat bantu pemeriksaan ini mudah dibawa dan dioperasikan pada saat dilakukan pemeriksaan. Alat bantu pemeriksaan ini mudah digerakan dan dipindahkan sehingga membantu kinerja radiografer.

b. Alat bantu pemeriksaan ini mampu memposisikan tubuh pasien dengan nyaman sehingga pasientidak perlu menahan keseimbangan untuk dapat berdiri dengan satu kaki.

c. Alat bantu pemeriksaan ini mempunyai penyangga kaki yang kuat dalam menopang kaki pasien dan dapatdiatur naik atau turun dengan mudah sesuai kebutuhan. 
d. Pada alat bantu ini juga terdapat pegangan bagi pasien supaya dapat membantu pasie nmenjaga keseimbangan ketika berdiri pada alat bantu tersebut.

e. Alat bantu pemeriksaan tersebut mampu menahan beban hingga $110 \mathrm{~kg}$ karena pada keempatkakinya dihubungkan menggunakan pipa sehingga alat tersebut menjadi kuat dan kokoh.

f. Alat bantu ini dapat mempermudah radiographer saat melakukan pemeriksaan knee joint dengan proyeksi AP weight bearing dan lateral weight bearing karenadenganmenggunakanalatinipasienm enjadilebihmudahuntukdiinstruksikan dan pasien pun merasa nyaman saat diposisikan oleh radiografer.

Setelah dilakukan uji kinerja berupa hasil check list dari 5 responden yang masingmasing memberi 5 jawaban, ada 1 jawaban dari 1 responden yang menjawab "TIDAK" pada pernyataan ketiga yang menanyakan apakah alat tersebut dapat mempercepat waktu pemeriksaan karena menurut responden tersebut berargumen bahwa alat tersebut tidak mempercepat waktu pemeriksaan apabila pasien dalam keadaan sangat kooperatif. Namun menurut penulis alat tersebut dapat mempercepat waktu pemeriksaan karena pasien akan menjadi mudah untuk diposisikan dan pasien menjadi nyaman saat dilakukan positioning.

Dari hasilpengujian uji kinerja tersebut yang mencapai $96 \%$, maka rancang bangun alat bantu pemeriksaan knee joint pada kasus osteoarthrithis dapat dikatakan sangat layak dan dapatdigunakan pada pemeriksaan radiografi knee joint proyeksi AP weight bearing dan lateral weight-bearing.

\section{Simpulan}

Alat bantu pemeriksaan knee joint ini memiliki beberapa bagian yaitu bagian alas yang terbuat dari papan kayu, penyangga kaki yang dapat diatur, dan pegangan pasien yang dilapisi dengan busa. Kerangka alat bantu tersebut menggunakan pipa stainless steel berdiameter 3 $\mathrm{cm}$ dengan ketebalan $1 \mathrm{~mm}$.

Berdasarkan uji fungsi yang telah dilakukan di Instalasi Radiologi RSUD Prof. Dr.Margono Soekarjo Purwokerto didapatkan hasil sebesar $100 \%$ sehingga alat bantu pemeriksaan knee joint pada kasus osteoarthrithis dikatakan berfungsi dengan baik dan layakdigunakan kepadapasien pada pemeriksaan knee joint pada kasus osteoarthrithis dengan proyeksi AP weight bearing dan lateral weight bearing guna pengambilan data.

Berdasarkan uji kinerja yang telahdilakukan di Instalasi Radiologi RSUD Prof. Dr. Margono Soekarjo Purwokerto yang melibatkan 5 responden yang merupakan radiografer, alat bantu pemeriksaan knee joint pada kasus osteoarthrithis dikatakan sangat layak dengan hasil persentase sebesar $96 \%$ dengan kelebihan mudah dioperasikan, mengurangi pergerakan pasien, dan membantu kinerja radiographer serta menghasilkan radiograf yang informatif.

\section{Daftar Pustaka}

Bushong, Stewart C. 2017. Radiologic Science for Technologists, Eleventh Edition. Missouri: Mosby inc.

Dirgahayuwono, Rikaz W.P. 2018. "ProsedurPemeriksaanRadiografi Knee Joint denganIndikasi Osteoarthritis di InstalasiRadiologi RSUD Prof. dr.MargonoSoekarjoPurwokerto".

KaryaTulisIlmiah. Purwokerto: Prodi DIII Teknik Radiodiagnostik dan Radioterapi, Jurusan Teknik Radiodiagnostik dan Radioterapi, PoltekkesKemenkes Semarang.

Evelyn C, Pearce. 2016. Anatomi dan FisiologiuntukParamedis. Jakarta: Gramedia Pustaka Utama.

Frank, Eugene D, Bruce W.L, Barbara J.S. 2012. Merril's Atlas of Radiographic Positioning \& Procedures, volume one, 12th edition. Missouri: Mosby inc.

Georgiev, Ts, R. Stoilov, M. Penkov, M. Ivanova, An Trifonov. 2018. Radiographic Assessment of Knee Osteoarthritis. https://www.researchgate.net/publication/311 875058. Diakses 28 Januari 2019.

Helmi, Zairin N. 2012. Buku Ajar GangguanMuskuloskeletal. Jakarta: SalembaMedika.

Keith K.W, Chan, Sit R.W.S, Wu R.W.K, Ngai A.H.Y. 2014. Clinical, Radiological, and Ultrasonographic Findings Related to Knee Pain Osteoarthritis. http://journals.plos.org/plosone/article?id. Diakses 15 Januari 2019.

Lampignano, John P. 2018. Bontrager's Textbook of Radiographic Positioning and Related Anatomy, Ninth Edition. Missouri: Mosby inc.

LaValley, Michael P, Sara McLaughlin, Joyce Goggins, Daniel Gale, Michael C, David T. 2005. The Lateral View Radiograph for Assessment of the Tibiofemoral Joint Space in Knee Osteoarthritis. Arthritis \& Rheumatism, Vol 52. 3542-3547. 
Pradani, Laila N.P. 2017. "RancangBangun Alat FiksasiPemeriksaan Hip Joint Proyeksi Antero-Posterior (AP)". KaryaTulisIlmiah. Purwokerto: Prodi DIII Teknik Radiodiagnostik dan Radioterapi, Jurusan Teknik Radiodiagnostik dan Radioterapi, PoltekkesKemenkes Semarang.

Sugiyono. 2009. MetodePenelitianKuantitatif, Kualitatif, dan R\&D. Bandung: Alfabeta 